\title{
STUDY OF SOME BIOMARKERS IN FRAIL ELDERLY
}

\author{
Abdallah M. Abdel-Rahman, Nabila A. Hussein, Hamed A. Deraz, Emam M. Esmayel, Waseem M. Seleem, \\ Marawan M. Atiyah, \\ Emad F. Hamed, Ayman Abd-Elrahman M.N. and Reda.A.K. Salem \\ Internal Medicine Department, Faculty of Medicine, Zagazig University
}

\begin{abstract}
Background: Frailty recognized as a common clinical syndrome associated wih a high rate of morbidity and mortality. Aim of the Study: This study aimed at assessing the value of determination of some biomarkers in identification and recruitment of frail elderly. The association between these biomarkers and stages of frailty were also assessed

Subjects and Methods : A total number of 100 elderly subjects (above 65 years old) were included in the work divided into three groups : Group 1 (non-frail) included 34 subjects (19 males and 15 females), their ages ranged from 66.3 to 72.9 with mean $67.6 \pm 3.3$ year; Group 2 (pre-frail) included 26 subjects ( 1 males and 15 females), their ages ranged from 65.5 to 73.1 with mean age of $69.3 \pm 3.8$ year and Group 3 (frail) included 40 subjects ( 25 males and 15 females), their ages ranged from $67.9 \pm$ to 78.3 with mean age of $73.1 \pm 5.2$ year.All subjects of this study were subjected to : thorough clinical examination, Anthropometric measures (including mid upper arm circumference, mid calf circumference, body mass index), Timed get-up-and-go test, hand grip strengh test and laboratory investigations (including complete blood picture, serum albumin, serum alanine transferase, INR. Prothrombin time and partial thromboplastin time, Cholesterol and C-reactive protein.

Results: In our study; frailty recorded higher prevalence than most of epidemiological studies. Regarding CRP, there was significant increase in CRP level in frail group $(27.4 \pm 8.1 \mathrm{mg} / \mathrm{l})$ compared to both pre-frail $(14.3 \pm 4.5 \mathrm{pg} / \mathrm{ml})$ and non-frail groups $(7.5 \pm 5.5 \mathrm{pg} / \mathrm{ml})$. Regarding cholesterol, there was significant decrease in cholesterol level in frail group (125.7 \pm 54.9) compared to both pre-frail $(168.1 \pm 17.2)$ and non-frail $(165.3 \pm 29.7)$ groups. Regarding TGUGT, it was prolonged in frail group compared to both pre-frail and non-frail groups.

Conclusions: There is high prevalence of frailty among studied elderly population, the causes of which need further studies to unravel. The changes in biomarkers noticed in our frail elderly may suggest its use in diagnosis and follow up of frailty, a suggestion that still in its infancy and needs further more studies to verify.

Key words : Frailty, C-reactive Protein and Timed get up and go test.
\end{abstract}

\section{INTRODUCTION}

O ver the past decade, clinicians and investigators have begun to recognize frailty as a common clinical syndrome associated with a high rate of morbidity and mortality, and therefore deserving rigorous investigations [1].

It has been postulated that there is a continuum of the severity of frailty ranging from non-frailty, prefrailty and frailty [2].

There is no single best definition of frailty [3]. The vernacular term frailty has been used to describe those who are feeble, weak, the most debilitated and the oldest old. Synonyms of frailty include defect, deficiency, error, failing, fallibility, imperfection, infirmity and susceptibility. Older adults or aged individuals who are lacking in general strength and are unusually susceptible to disease or to other infirmity [4].

Furthermore, no single altered system or etiology defines frailty $[\mathbf{5 , 6 ]}$.

Bold et al. [7] reported that clinical markers or indicators are insufficient to differentiate the frailty process from normal aging, and they gave rise to the necessity to detect frailty at a pre-clinical stage with the help of biomarkers.
Evaluation of alterations in human biomarkers and their relationships to differing models of frailty may assist in the determination of the initiation of the processes that eventually led to frailty [8].

\section{SUBJECTS AND METHODS}

This work had been carried out in Internal Medicine Departments, Faculty of Medicine, Zagazig University during the year 2011.

\section{SUBJECTS :}

A total number of 100 elderly subjects (above 65 years old) were included in the work recruited from those attending Zagazig University Hospitals for management of cataract and from day care center for geriatrics in Zagazig Governorate during the year 2011.

\section{Ethical clearance :}

Informed concent from the patients if possible or from their relatives to participate in the study.

Inclusion criteria: we only considered subjects whose ages were above 65 years old and free of diseases as possible, for inclusion.

Matching of dietary habits and socioeconomic status were also criteria for inclusion. Exclusion criteria: subjects who had any known disabilities and/or comorbidities were excluded. Also subjects with a history of the following diseases were 
excluded (diabetes mellitus, coronary heart diseases and self-reported history of stroke, peripheral vascular diseases, cancer and respiratory diseases). Those treated with non-steroidal anti-inflammatory drugs or with cortico-steroids were also excluded.

They were divided to three groups according to Fried criteria of frailty [9]:

Group 1: Included 34 of non-frail subjects, it included 19 males and 15 females, their ages Criteria used to define physical frailty, Adopted from Fried et al. [9]. One must have 3 of the 5 following criteria for frailty, 1-2 for prefrail and zero for non-frail.

\begin{tabular}{|c|c|c|c|c|}
\hline Frailty Criteria & \multicolumn{2}{|c|}{ Male } & \multicolumn{2}{|c|}{ Female } \\
\hline $\begin{array}{l}15 \text { foot walk } \\
\text { time-slowness }\end{array}$ & $\begin{array}{l}\text { Height }<173 \\
\text { Height }>173\end{array}$ & $\begin{array}{l}>7 \text { seconds } \\
>6 \text { seconds }\end{array}$ & $\begin{array}{l}\text { Heigh }<159 \\
\text { Height }>159\end{array}$ & $\begin{array}{l}>7 \text { seconds } \\
>6 \text { seconds }\end{array}$ \\
\hline $\begin{array}{l}\text { Hand grip strength } \\
\text { weakness }\end{array}$ & $\begin{array}{c}\text { BMI }<24 \\
\text { BMI 24.1-26 } \\
\text { BMI 26.1-28 } \\
\text { BMI }>28\end{array}$ & $\begin{array}{l}<29 \\
<30 \\
<30 \\
<32\end{array}$ & $\begin{array}{c}\text { BMI }<23 \\
\text { BMI 23.1-26 } \\
\text { BMI 26.1-29 } \\
\text { BMI }>29\end{array}$ & $\begin{array}{l}\text { M17 } \\
<17.3 \\
<18 \\
<21\end{array}$ \\
\hline $\begin{array}{l}\text { Unintentional weight } \\
\text { loss-shrinking }\end{array}$ & \multicolumn{4}{|c|}{$\begin{array}{l}\text { Greater than } 5 \% \text { weight loss in the last year (objective from relatives or subjective } \\
\text { from patients and is not due to dieting or exercise) }\end{array}$} \\
\hline $\begin{array}{l}\text { Physical } \\
\text { Activity* } \\
\text { Low activity }\end{array}$ & \multicolumn{2}{|c|}{$<383$ kilocalories/wk } & \multicolumn{2}{|c|}{$<270$ kilocalories/wk } \\
\hline $\begin{array}{l}\text { Exhaustion } \\
\text { fatigue }\end{array}$ & \multicolumn{4}{|c|}{$\begin{array}{l}\text { A score of } 2 \text { or } 3 \text { on either question of the CES-D How often in the last week did you } \\
\text { feel this way? } \\
\text { - I felt that everything I did was an effort } \\
\text { - I could not get going } \\
0=1 \text { day, } 1=1-2 \text { days, } 2=2,3,4 \text { days, } 3=\text { more than } 4 \text { days }\end{array}$} \\
\hline
\end{tabular}

ranged from 66.3 to 72.9 with mean $67.6 \pm 3.3$ year.

Group 2 : Included 26 of pre-frail subjects, it included 11 males and 15 females, their ages ranged from 65.5 to 73.1 with mean age of $69.3 \pm 3.8$ year.

Group 3: Included 40 subjects with criteria of frailty, it included 25 males and 15 females, their ages ranged from 67.9 to 78.3 with mean age of $73.1 \pm 5.2$ year. 
with criteria of frailty, it included 25 males and 15 females, their ages ranged from 67.9 to 78.3 with mean age of $73.1 \pm 5.2$ year.

Table (1) showed significant difference between the studied groups regarding both age (Fig. 1) and BMI (Fig. 2), while there was no significant difference between them as regards sex.

Table (2) showed highly significant difference between the studied groups regarding TGUGT (Fig. $3)$.

Table (3) showed highly significant difference between the studied groups regarding MAC, while there was significant difference between them regarding CC (Fig. 4).

Table (4) showed highly significant difference between the studied groups as regards serum cholesterol (Fig. 6), ALT (Fig. 8), WBCs (Fig. 11) and CRP (Fig. 12) levels while there was significant difference between the studied groups as regards $\mathrm{HB}$ level (Fig. 5), but regarding serum albumin, PT and INR levels there was no significant difference between them (Fig. 7, 9 and 10).

Table (1) : Means \pm standard deviation (SD) of age and BMI with Chi-square test for prevalence of gender among the studied groups.

\begin{tabular}{|c|c|c|c|c|c|}
\hline Variable & Non-frail & Pre-frail & Frail & $\mathbf{F}$ & $\mathbf{P}$ \\
\hline Age (year) & $67.6 \pm 3.3$ & $69.3+3.8$ & $73.1+5.2$ & 8.67 & $<0.05(\mathrm{~S})$ \\
\hline Sex & & & & $\overline{X^{2}}$ & \\
\hline Females & $33.3 \%$ & $33.3 \%$ & $33.3 \%$ & 2.612 & 0.271 \\
\hline Males & No (15) & No (15) & No (15) & & (NS) \\
\hline BMI $\left(\mathrm{kg} / \mathrm{m}^{2}\right)$ & $27.7 \pm 3.4$ & $27.9 \pm 2.3$ & $25.6 \pm 3.3$ & 5.90 & $<0.05(\mathrm{~S})$ \\
\hline
\end{tabular}

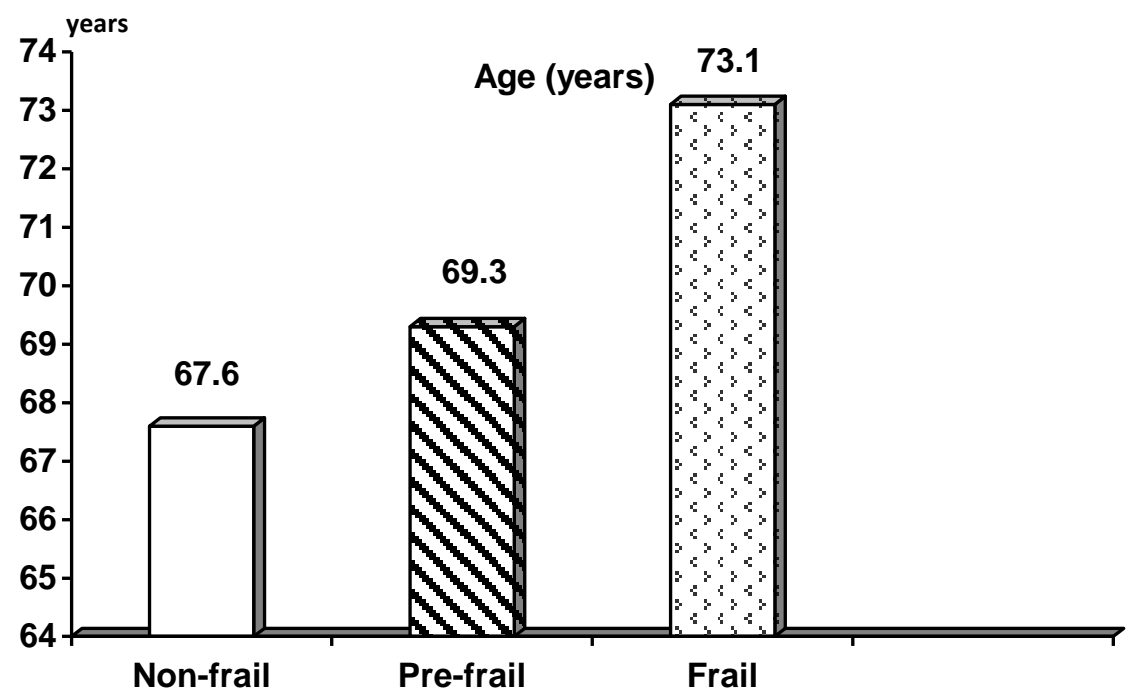

Fig. (1) : Showing comparison of mean \pm SD of age among the non-frail, pre-frail and frail groups of elderly 


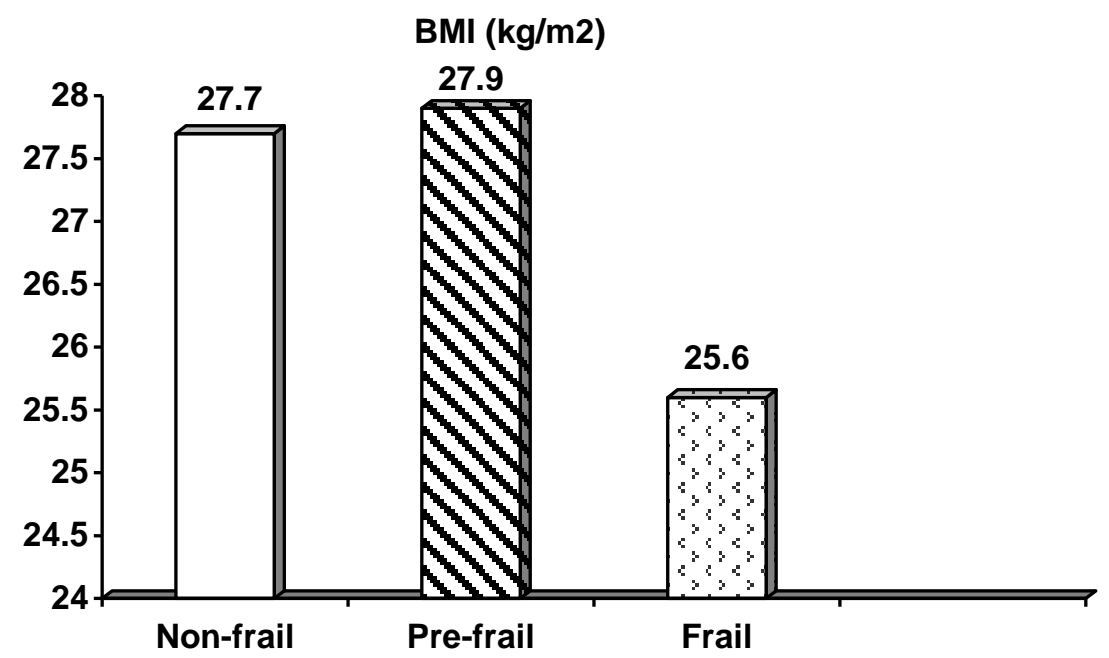

Fig. (2) : Comparison of mean \pm SD of BMI in the three groups of subjects

Table (2): Chi-square test for prevalence of normal and prolonged timed get-up and go test among the studied groups

\begin{tabular}{|c|c|c|c|c|c|c|c|c|}
\hline \multirow{2}{*}{$\begin{array}{l}\text { TGUGT } \\
\text { (seconds) }\end{array}$} & \multicolumn{2}{|c|}{ Non-frail } & \multicolumn{2}{|c|}{ Pre-frail } & \multicolumn{2}{|c|}{ Frail } & \multirow{2}{*}{$\mathbf{F}$} & \multirow{2}{*}{$\mathbf{P}$} \\
\hline & No & $\%$ & No & $\%$ & No & $\%$ & & \\
\hline Normal & 27 & 62.8 & 13 & 39.2 & 3 & 7 & \multirow{2}{*}{39.47} & \multirow{2}{*}{$0.01(\mathrm{HS})$} \\
\hline Prolonged & 7 & 12.3 & 13 & 22.8 & 37 & 64.9 & & \\
\hline
\end{tabular}

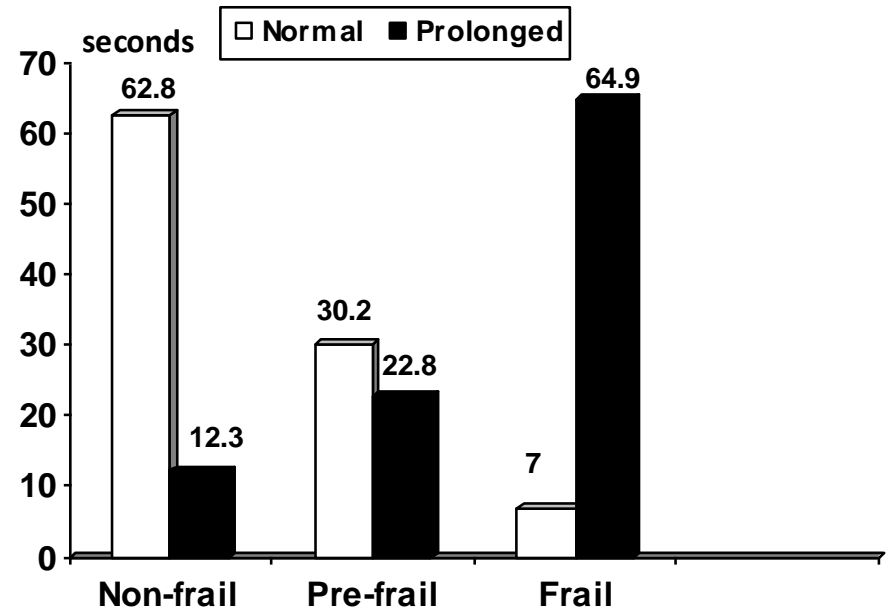

Fig. (3) : The ratios between prolonged and normal TGUGT in the three studied groups 
Table (3) : Mean \pm SD of anthropometric measurement (MAC and CC) among the studied groups

\begin{tabular}{lccccc}
\hline \multicolumn{1}{c}{ Variable } & Non-frail & Pre-frail & Frail & F & P \\
\hline MAC $(\mathrm{cm})$ & $33.2 \pm 3.6$ & $32.5 \pm 4.1$ & $26.1 \pm 5.8$ & 24.61 & $<0.01(\mathrm{HS})$ \\
\hline $\mathrm{CC}(\mathrm{cm})$ & $42.7 \pm 4.7$ & $41.0 \pm 5.7$ & $34.6 \pm 6.1$ & 21.20 & $<0.05(\mathrm{~S})$ \\
\hline
\end{tabular}

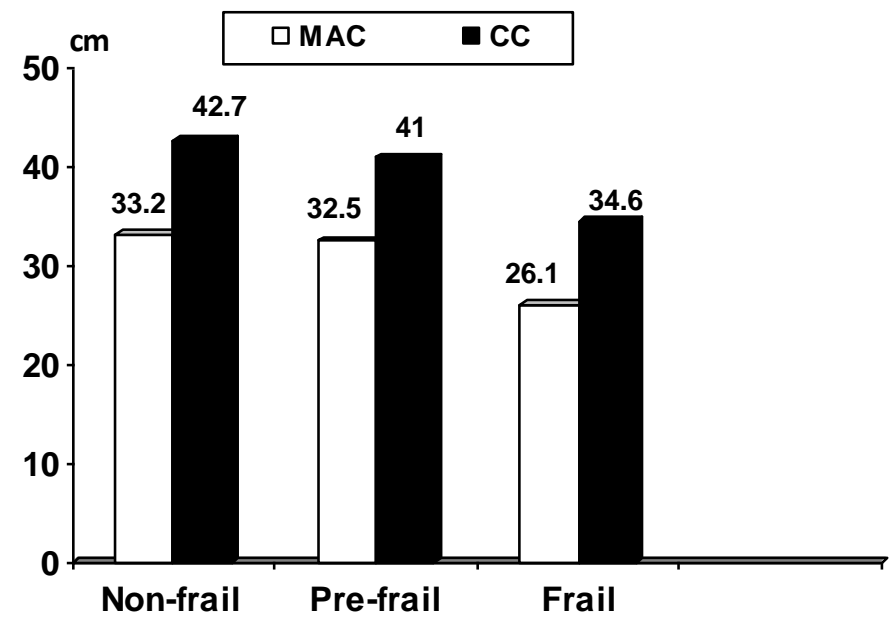

Fig. (4) : Comparison of mean \pm SD of MAC and CC in the three groups of subjects

Table (4) : Means \pm Standard deviation of some biomarkers of liver functions among elderly subjects, in three groups of the study (non-frail, pre-frail and frail).

\begin{tabular}{lccccc}
\hline \multicolumn{1}{c}{ Variable } & Non-frail & Pre-frail & Frail & F & P \\
\hline HB $(\mathrm{g} / \mathrm{dl})$ & $12.8 \pm 1.7$ & $13.3 \pm 1.9$ & $10.4 \pm 2.6$ & 18.9 & $<0.05(\mathrm{~S})$ \\
\hline $\begin{array}{l}\text { Serum cholesterol } \\
(\mathrm{mg} / \mathrm{dl})\end{array}$ & $165.3 \pm 29.7$ & $168.1 \pm 17.2$ & $125.7 \pm 54.9$ & 12.60 & $<0.01(\mathrm{HS})$ \\
\hline $\begin{array}{l}\text { Serum albumin } \\
(\mathrm{g} / \mathrm{dl})\end{array}$ & $4.0 \pm 0.76$ & $4.13 \pm 0.82$ & $4.34 \pm 0.57$ & 0.072 & $0.93(\mathrm{NS})$ \\
\hline ALT $(\mathrm{u} / \mathrm{l})$ & $39.05 \pm 11.27$ & $37.5 \pm 17.7$ & $20.6 \pm 16.5$ & 16.28 & $<0.01(\mathrm{HS})$ \\
\hline PT $(\mathrm{seconds})$ & $17.2 \pm 9.9$ & $15.0 \pm 5.2$ & $16.7 \pm 4.6$ & 0.81 & $0.44(\mathrm{NS})$ \\
\hline INR & $1.4 \pm 0.90$ & $1.2 \pm 0.53$ & $1.3 \pm 0.34$ & 0.82 & $0.44(\mathrm{NS})$ \\
\hline $\begin{array}{l}\text { WBCs } \\
\chi 103(\mathrm{cmm})\end{array}$ & $8.7+1.6$ & $10.9+2.7$ & $14.22+3.7$ & 32.9 & $<0.01(\mathrm{HS})$ \\
\hline $\mathrm{CRP}(\mathrm{mg} / \mathrm{l})$ & $7.5+5.5$ & $14.3+4.5$ & $27.4+8.1$ & 12.77 & $0.01(\mathrm{HS})$ \\
\hline
\end{tabular}




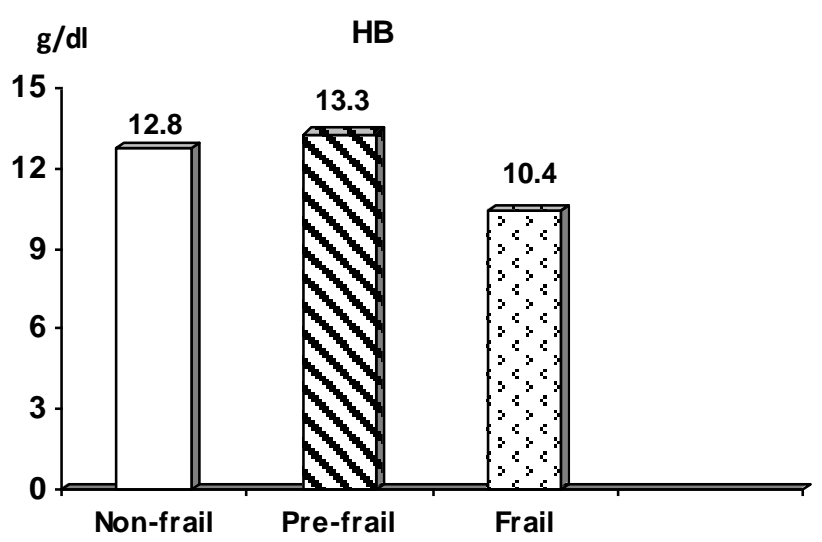

Fig. (5) : Comparison of mean $\pm \mathrm{SD}$ of $\mathrm{Hb} \%$ in the three groups

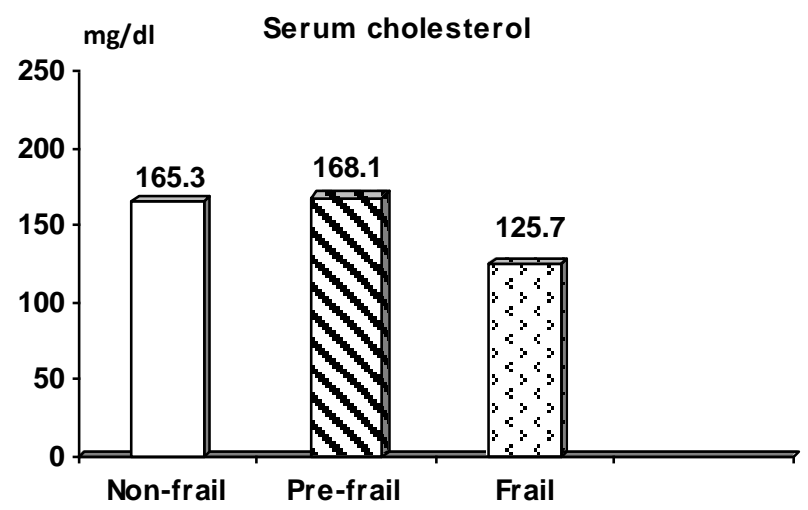

Fig. (6): Comparison of mean \pm SD of serum cholesterol in the three studied groups

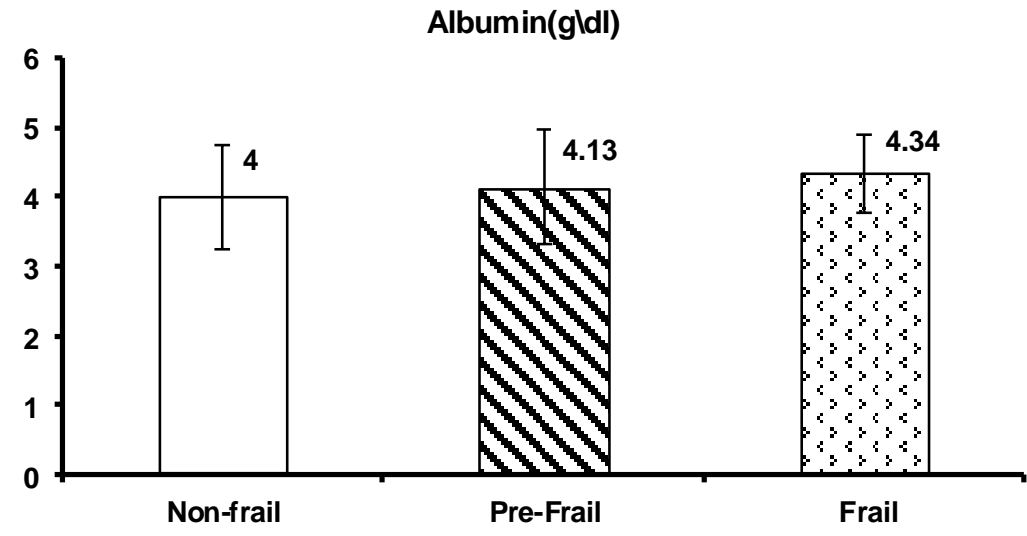

Fig. (7): Comparison of mean $\pm \mathrm{SD}$ of serum albumin in the three studied groups. 
Alt(ull)

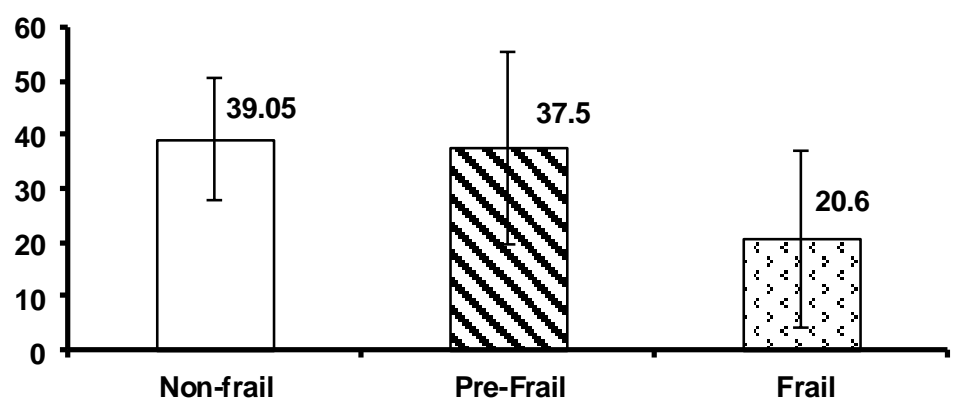

Fig. (8): Comparison of mean $\pm \mathrm{SD}$ of serum ALT in the three studied groups.

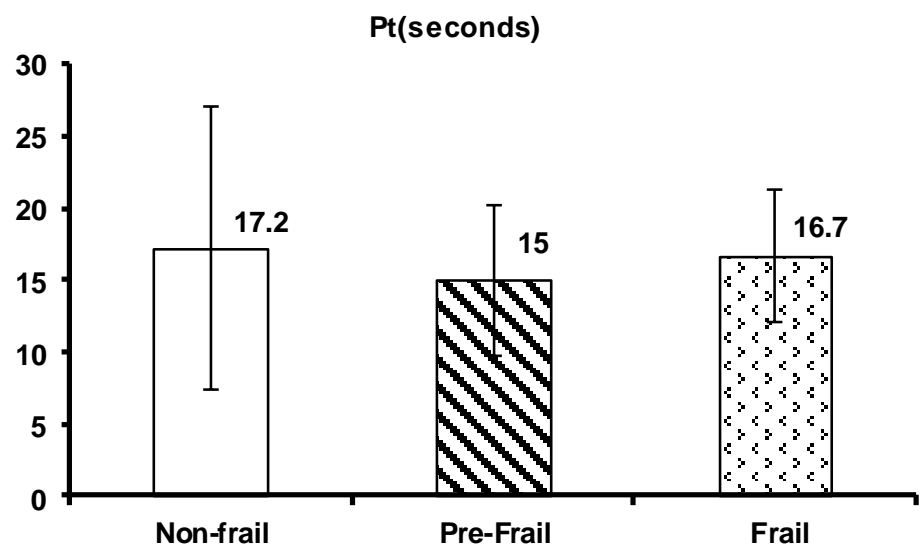

Fig. (9): Comparison of mean $\pm \mathrm{SD}$ of serum PT in the three studied groups.

INR

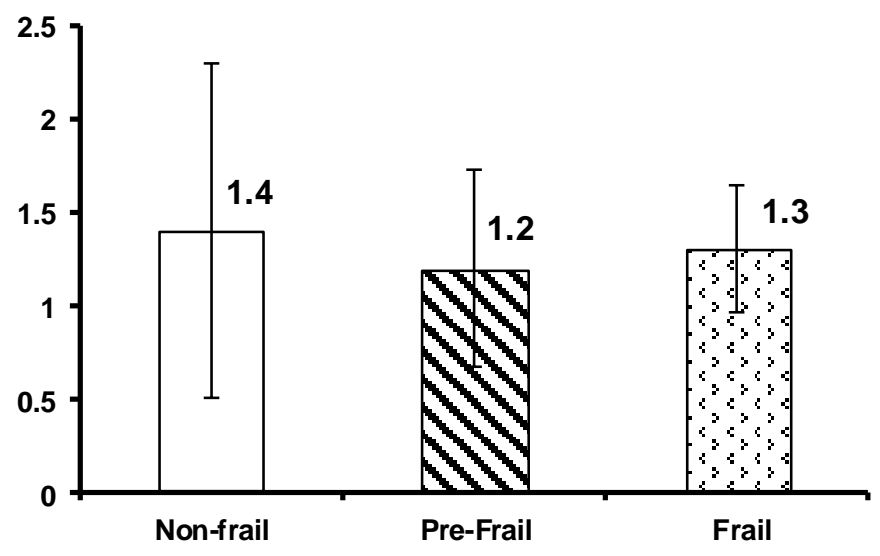

Fig. (10): Comparison of mean $\pm \mathrm{SD}$ of serum INR in the three studied groups 
WBCs

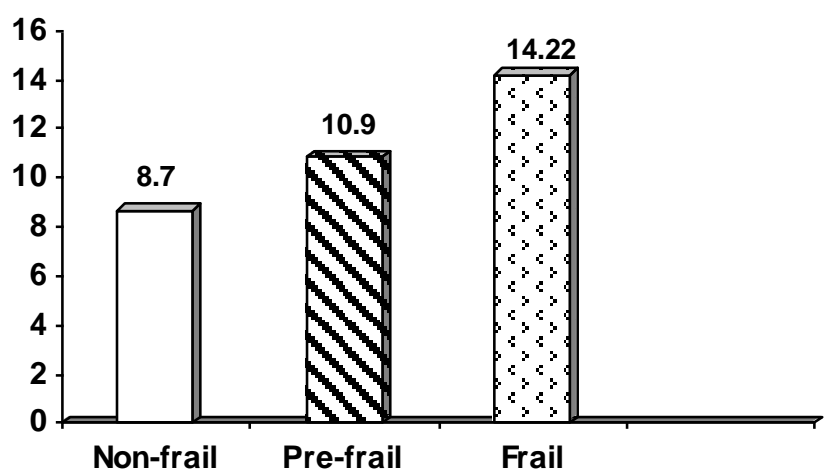

Fig. (11) : Comparison of mean \pm SD of WBCs in the three groups of subjects

\section{CRP}

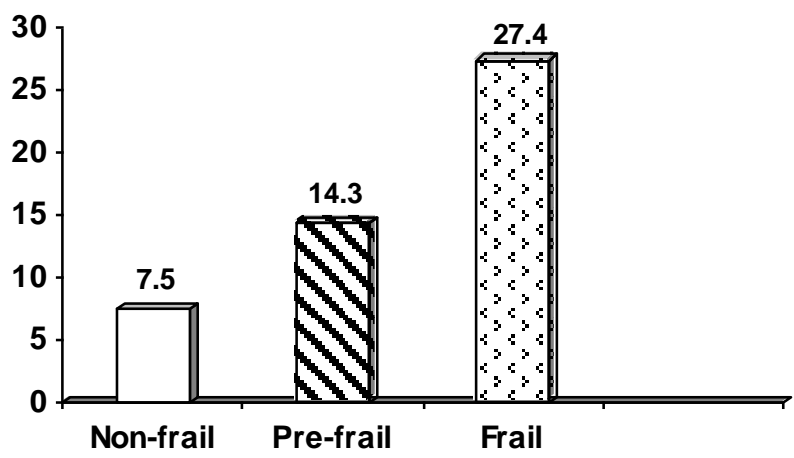

Fig. (12): Comparison of mean \pm SD of CRP in the three groups of subjects

\section{DISCUSSION}

Frailty has been recognized as a common clinical syndrome associated with a high rate of morbidity and mortality [1].

As regard age of subjects, our study revealed significant elevation in age of frail subjects $(731 \pm$ 5.2 year), compared to both pre-frail $(69 \pm 3.8$ year $)$ and non-frail with non significant increase in prefrail compared to non-frail $(67.6 \pm 3.3$ year). These results give support to the study of Woods et al. [15] that reported significant association between age and frailty.

Our study showed no significant association between gender and frailty. However, some investigators reported significant association between female gender and frailty [16], and this may be explained by the included females in their studies suffered from many other comorbidities.

In our study, we assessed several potential biomarkers of frailty. As regard hemoglobin concentration, we found significant decrease in $\mathrm{Hb} \%(10.4 \pm 2.6 \mathrm{~g} / \mathrm{dl})$ in frail group compared to both pre-frail $(13.3 \pm 1.9$ $\mathrm{g} / \mathrm{dl})$ and non-frail $(12.8 \pm 1.7 \mathrm{~g} / \mathrm{dl})$ with no significant difference between pre-frail and non-frail. This agrees with that obtained by Chaves et al. [17] who demonstrated a direct link in elderly women between the presence of anemia and the occurrence of frailty. The association between frailty and anemia may be due to decrease intake of foods, vitamins and iron or due to many causes of chronic blood loss which are common in elder persons.

As regard white blood cells count, we found significant increase in WBCs count $(14.22 \pm 3.7$ $\mathrm{cmm})$ in frail group compared to both pre-frail (10.9 $\pm 2.7 \mathrm{cmm})$ and non-frail $(8.7 \pm 1.6 \mathrm{cmm})$ with significant elevation in pre-frail compared to nonfrail.

This agrees with that obtained by Ruggiero et al. [18] who found direct relationship between frailty and elevated counts of WBCs (specifically neutrophil and 
monocyte counts) and demonstrated potential synergistic interaction between WBCs and IL-6 in their association with frailty.

Frailty is associated with increase in WBCs as well as CRP (which are recognized as an important markers of systemic inflammation), which suggests a role of inflammation in aging [19].

Interestingly, WBCs is the only biomarker in our study that showed significant difference between pre-frail and non-frail groups, suggesting that it may be useful for detection of pre-frailty, a suggestion that needs further studies to clarify.

As regard serum albumin level, we found no significant difference between the three groups of the study (frail, pre-frail and non-frail) but this differ from other numerous studies that have reported higher mortality in community-dwelling older people with a low serum albumin level. Reuben et al. [20] reported that the relative risk for mortality in healthy non-disabled older persons was 2.2 times higher in subjects with an albumin level below $4 \mathrm{~g} / \mathrm{dl}$. Also Takata et al. [21] found that lower serum albumin concentrations were an independent predictor of mortality in 70 years old people in communitydwelling population.

However, in agreement with our results, Schalk et al. [22] found no association between lower serum albumin and functional decline in the elderly. This difference may be due to different nutritional status in these studies or due to the presence of diseases that affect serum albumin level.

As regard serum ALT, we found significant decrease in ALT levels (20.6 $\pm 16.5 \mathrm{u} / \mathrm{l})$ in frail group compared to both pre-frail $(37.5 \pm 17.7 \mathrm{u} / \mathrm{l})$ and non-frail $(39.0 \pm 11.2$ u.1) with no significant difference between pre-frail and non-frail. This agrees with the study of David et al. [23] that revealed a substantially lower ALT level in older persons. The presence of significant decrease in serum ALT level in frail elderly compared to both pre-frail and non-frail in the absence of significant changes in other liver function tests may point to the value of low serum ALT as a biomarker of frailty, a result that needs further studies to verify.

As regard serum CRP level, we found significant increase in CRP levels $(27.4 \pm 8.1 \mathrm{mg} / \mathrm{l})$ in frail group compared to both pre-frail $(14.3 \pm 4.5 \mathrm{mg} / \mathrm{l})$ and non-frail $(7.5 \pm 5.5 \mathrm{mg} / \mathrm{l})$ with no significant difference between pre-frail and non-frail. This agrees with that obtained by Walston and Collegues [24] who showed significant association of elevated CRP level with frailty and Puts et al. [25] who have further confirmed these findings. It also go with results obtained by
Yoshida et al. [26], who found elevated CRP levels in elderly wih poor physical performance. Our results may give support to the theory of inflammaging.

As regard serum cholesterol level, we found significant decrease in cholesterol level $(125.7 \pm 54.9$ $\mathrm{mg} / \mathrm{dl}$ ) in frail group compared to both pre-frail $(168.1 \pm 17.2 \mathrm{mg} / \mathrm{dl})$ and non-frail $(165.3 \pm 29.7 \mathrm{mg} / \mathrm{dl})$ with no significant difference between pre-frail and non-frail. This agrees with that obtained by Reiner et al. [27] who identified low serum cholesterol as a risk factor for frailty. Our results also agree with that of Schalk et al. [22] who reported that low cholesterol level might be associated with decline in functional status which is one of the components of frailty.

As regard MAC, we found significant decrease in MAC $(26.1 \pm 5.8 \mathrm{~cm})$ in frail group compared to both pre-frail $(32.5 \pm 4.1 \mathrm{~cm})$ and non-frail $(33.2 \pm 3.6 \mathrm{~cm})$ with no significant difference between pre-frail and non-frail. This agrees with that obtained by Cesari et al. [28] who found that low MAC was significantly associated with an increased 15 -year mortality risk in men and women and Flegal [29] who found that low MAC was more strongly associated with mortality than low BMI. Supporting our results, Wijnhoven et al. [30] reported that MAC seemed a more feasible and valid anthropometric measure of thinness than BMI in elderly.

As regard MCC, we found significant decrease in MCC $(34.6 \pm 6.1 \mathrm{~cm})$ in frail group compared to both pre-frail $(41.0 \pm 5.7 \mathrm{~cm})$ and non-frail $(42.7 \pm 4.7 \mathrm{~cm})$ with no significant difference between pre-frail and non-frail. This agrees with that obtained by Cesari et al. [28] who found that low MCC was significantly associated with an increased 15-year mortality risk in men and women and Wijnhoven et al. [30] who found significant association between MCC and mortality in elderly.

As regard BMI, we found significant decrease in BMI $\left(25.6+3.3 \mathrm{~kg} / \mathrm{m}^{2}\right)$ in frail group compared to both pre-frail $\left(27.9 \pm 2.3 \mathrm{~kg} / \mathrm{m}^{2}\right)$ and non-frail $(27.7 \pm 3.4$ $\mathrm{kg} / \mathrm{m}^{2}$ ) with no significant difference between pre-frail and non-frail. This agrees with that obtained by Marchesini et al. [31] who found increased mortality risk at low BMI values in old age and agree with Bahat et al. [32] who concluded that better functional status in elderly was associated with higher BMI even in BMI $\geq 30 \mathrm{~kg} / \mathrm{m}^{2}$.

As regard TGUGT, we found significant prolongation in TGUGT in frail group compared to both pre-frail and non-frail with no significant difference between pre-frail and non-frail. This agrees with that obtained by Mathias et al. [12] who 
found prolonged TGUGT in geriatric patients and suggested that it can serve as performance test.

The presence of non significant difference in some studied biomarkers (except WBCs) between pre-frail and non-frail groups of elderly may suggest that these changes appear late in the frail group only, and this motivate the search for other biomarkers that can differentiate between pre-frail and non-frail elderly in further studies.

Our results suggest that the observed changes in some biomarkers with frailty; increasing age, WBCs, CRP and TGUGT and decreasing in ALT, $\mathrm{Hb} \%$, cholesterol, MAC, CC and BMI can suggest their use to detect frailty and to assess its degree of severity.

\section{CONCLUSIONS AND RECOMMENDATIONS}

1- There is high prevalence of frailty among studied elderly population, the causes of which need further studies to untravel.

2- The changes in biomarkers noticed in our frail elderly may suggest its use in the diagnosis and follow up of frailty, a suggestion that still in its infancy and needs further studies to verify.

3- The significant elevation of CRP and WBCs in frail elderly, which are markers of inflammation, may give support to the theory of inflammaging. 4- Being the only biomarker that differed significantly in pre-frail compared to non-frail group, further studies are suggested to assess ability of WBCs count in the detection of preclinical states of frailty as a single easy test to detect frailty while CRP increase in a later stage.

5- The impact of frailty on the quality of life is an important area of research, the results of which may help successful aging.

6- Further studies are also needed to assess whether frailty is a reversible event.

\section{REFERENCES}

1- Inkaki M, Iturbe A, Gome J et al. (2010): The frail elderly, detection and treatment. Aten Primaria; 42: 388-93.

2- Vankan G, Rolland Y, Bergman H et al. (2010) : The IANA task force on frailty assessment of older people in clinical practice. J Nutr Health and Aging; 12: 2936.

3- Singh M, Alexander K, Rober VL et al. (2008): Frailty and its potential relevance to cardiovascular care. Mayo Clinic Proceedings; 83(10): 1146-53.

4- Hogan DB, Macknight C and Bergman H (2003) : Models, definitions and criteria of frailty. Aging Clinical and Experimental Research; 15 (Supplement 3): 1-29.

5- Fried IP, Ferrucci L, Darer J et al. (2004): Untangling the concepts of disability, frailty and comorbidity; Implications for targeting and care. J Gerontol A Biol Sci Med Sci; 59(3) : 255-63.

6- Fried IP, Hadley EC, Walston JD, et al. (2005) : From bedside to bench : Research agenda for frailty. Sci Aging Knowledge Environ (31): Pe24. [Erratum in: Sci Aging Knowledge Environ (41): er24].

7- Bold P, Drame M, Jolly D et al. (2011): Frailty : Learnings from the cohort study and future perspectives for the research. Geiatr Psychol Newopsychiatr Vicil; 9(2): 135-49.

8- Williams JER (2010): Characteristics of frailty in community. Dwelling Eldes. Ph.D Dissertation. The Ohio State University, p. 83.

9- Fried I, Tangen C, Walston J et al. (2001): Frailty in older persons. Evidence for a phenotype. J Gerontol Med Sci; 56: M146-56.

10- Price CP et al. (1987): Development and Validation of a pactical-enhanced turbidi-metric Immunoassay for C-reactive protein. J Immunol Methods; 99: 205-11.

11- Eda S et al. (1998): Development of a new microparticle-enhanced turbidimetric assay for Creactive protein with superior features in sensitivity and dynamic range. J Clin Lab Anal; 12: $137-44$.

12- Mathias S, Nayak US, Isaaes B (1986): Balance in elderly patients: The "get-up and go" test. Arch Phys Med Rehabil; 67: 34-22.

13- Davis B et al. (2000): Physical fitness and fitness testing. In: Davis, B et al. Physical Education and the study of sport. $4^{\text {th }}$ ed. Spain: Harcourt p. 123.

14- Clerke A (2005): Effects of hand shape on maximal isometric grip strength in teenagers. Journal of Hand Therapy; 18(1): 19-29.

15- Woods NF, La Croix AZ, Gray SL et al. (2005): Women's Health Initiative. Fraily: Emergence and consequences in women aged 65 and older in the Women's Health Initiative Observational Study. J Am Geriatr Soc; 53(8): 1321-30.

16- Ottenbacher KJ, Ostir GV, Peek MK et al. (2005): Frailty in older Mexican Americans. J Am Geriatr Soc; 53(9): 1524-31.

17- Chaves PH, Semba RD, Leng SX et al. (2005): Impact of anemia and cardio-vascular disease on frailty status of community-dwelling older women: the women's health and aging studies I and II. J Gerontol A Biol Sci Med Sci; 60(6): 729-35.

18- Ruggiero C, Metter EJ, Cherubini A et al. (2007) : White blood cell count and mortality in the Baltimore Longitudinal Study of Aging. J Am Coll Cardiol; 49(18):1841-50.

19- Yao X, Huifen I and Leng S (2011): Inflammation and immune system alteration in frailty. Clin Geriatr Med; 27: 79-87.

20- Reuben DB, Cheh AI, Harris TB et al. (2002): Peripheral blood markers of inflammation predict 
mortality and functional decline in highfunctioning community-dwelling older persons. J Am Geriatr Soc; 50: 638-44.

21- Takata Y, Ansai T, Yoshihara A and Miyazaki H (2012) : Serum albumin levels and year mortality in a community dwelling 70-year-old population. Arch Gerontol Geriatre; 54: 39-43.

22- Schalk B, Visser M, Degg H et al. (2004): Lower level of serum albumin and total cholesterol and future decline in functional performance in older persons. Age and Aging; 33: 266-72.

23- David I, Blyth F, Creast H et al. (2010): The association of alanine transaminase with aging, frailty and mortality. J Gerontol A Biol Sci Med; 65: 712-17.

24- Walston JD, Newman AB, Guralnick JM et al. (2005): From bedside to bench: Research agenda for frailty. Science of Aging Knowledge Environment; 31: 24.

25- Puts MT, Visser M, Twisk JW et al. (2005): Endocrine and inflammatory markers as predictors of frailty. Clin Endocri (Oxf); 63(4) : 403-11.

26- Yoshida Y, Iwara H, Shu K et al. (2010): Association between CRP level and physical performance in community dwelling in Japan. Arch Gerontol Geriatr; 51(2): 164-68.

27- Reiner A, Aragaki A, Gray S et al. (2009): Inflammation and thrombosis biomarkers and incident frailty in post-menopausal women. Am J Med; 22: 947-54.

28- Gesari M, Pahor M, Lauretani F et al. (2009): Skeletal muscle and mortality results from the In Chianti Study. J Gerontol A Biol Sci Med Sci; 64(3): 377-84.

29- Flegal KM, Graubard BI, Williamson DF et al. (2007): Impact of smoking and preexisting illness on estimates of the fractions of deaths ssociated with under-weight, overweight and obesity in the US population. Am J Epidemiol; 166(8):975-82.

30- Wijnhoven H, Heyman M, Visser M et al. (2010): Low mid-upper arm circumference, calf circumference and body mass index and mortality in older persons. J Gerontol A Biol Sci Med Sci; 65A (10): 1107-14.

31- Marchesini G, Moscatiello S, Di Domizio S, Forlani G (2008): Obesity-associated liver disease. J Clin Endocrinol Metab; 93: S74-S80.

32- Bahat G, Tufan F, Saka B et al. (2012): Which BMI is better in the elderly for functional status. Arch Gerontol Geriatr; 54: 78-81. 